\title{
Cerebral vascular disease
}

National Diabetes Information Clearinghouse (NDIC)

\section{Definitions}

Blood vessels

Defined by National Diabetes Information Clearinghouse (NDIC)

Stroke

Defined by National Diabetes Information Clearinghouse (NDIC)

Source

National Diabetes Information Clearinghouse (U.S.). (2009). The diabetes dictionary. [Bethesda, Md.]: U.S. Dept. of Health and Human Services, National Institutes of Health, National Institute of Diabetes and Digestive and Kidney Diseases, National Diabetes Information Clearinghouse.

Damage to blood vessels in the brain. Vessels can burst and bleed or become clogged with fatty deposits. A stroke results when blood flow is interrupted and brain cells die or are damaged. 